\title{
Genetic parameters of milk ELISA scores for Johne's disease
}

\author{
S. A. Attalla, ${ }^{\star} \dagger$ A. J. Seykora, ${ }^{* 1}$ J. B. Cole, $\ddagger$ and B. J. Heins ${ }^{*}$ \\ *Department of Animal Science, University of Minnesota, St. Paul 55108 \\ †Cattle Information System, Faculty of Agriculture, Cairo University, Giza, Egypt \\ ‡Animal Improvement Programs Laboratory, ARS-USDA, Beltsville, MD 20705-2350
}

\section{ABSTRACT}

The objective of this study was to estimate genetic parameters of antibody response to Mycobacterium avium ssp. paratuberculosis using routinely collected Minnesota Dairy Herd Improvement milk ELISA tests. After all edits, 25,809 tests from 21,514 Holstein cows in 282 Johne's positive herds were available for analysis. The Johne's test results were analyzed both as a binary trait (positive or negative) and as a linear trait as the transformed ELISA optical density [ln(OD)]. Significant fixed effects in the model were age at test date, days in milk, and laboratory negative control; random effects were herd test date, animal effect, and permanent environment effect. Transformed ELISA optical density increased with age at test day and days in milk. Heritability estimates ranged from 0.065 to 0.095 . Percentage of variation explained by maternal effects ranged from 1.3 to $2.29 \%$. Repeatabilities ranged from 0.380 to 0.433 . Statistically significant correlations between the sire solutions for $\ln (\mathrm{OD})$ for 154 bulls with at least 30 daughters in the analysis and their USDA predicted transmitting abilities were as follows: fat yield, -0.199 ; protein yield, -0.179 ; productive life, -0.292 ; and Net Merit, -0.339 . These correlations suggest that selection for productive life or Net Merit also will improve resistance to Johne's disease.

Key words: heritability, paratuberculosis, Johne's disease

\section{INTRODUCTION}

Paratuberculosis in ruminants, also commonly referred to as Johne's disease, manifests itself as chronic enteritis in the small intestine and is caused by $\mathrm{Myco-}$ bacterium avium ssp. paratuberculosis (MAP). The disease causes losses of $\$ 200$ million annually in the United States (Kovich et al., 2006). Costs include decreased milk production, reduced cow salvage value, premature culling, and veterinary expenses. The USDA's Animal

Received August 7, 2009.

Accepted December 7, 2009.

${ }^{1}$ Corresponding author: seyko001@umn.edu and Plant Health Inspection Service Dairy 2007 study (NAHMS, 2007) indicated that $68.1 \%$ of US dairy operations were infected with MAP and that $31.7 \%$ of dairies participated in a Johne's control program. Wells et al. (1998) reported that Johne's disease was one of the most important diseases when considering zoonotic risks, international trade implications, and animal welfare concerns, in addition to the impact on animal productivity.

Calves are generally infected with MAP before 6 mo of age (NAHMS, 1997). Transmission of infection usually occurs orally through fecal ingestion, but may also occur via consumption of colostrum or milk from infected cows or through the placenta before birth. Once an animal is infected, the incubation period for MAP is generally $2 \mathrm{yr}$ or longer before clinical manifestation of the disease occurs. Clinical signs of Johne's disease include worsening diarrhea, weight loss, and decreased milk production despite a normal appetite. There is currently no cure for MAP infection or Johne's.

Several studies have indicated that heritability for resistance to Johne's disease seems to be similar to that for resistance to other diseases, averaging around 0.10. Based on postmortem tests of 3,020 Dutch cows, Koets et al. (2000) reported heritabilities for Johne's disease of 0.06 for nonvaccinated animals to 0.09 for vaccinated animals. Gonda et al. (2006) estimated heritabilities of serum ELISA test for 4,603 US Holsteins of 0.16 using a linear model and 0.09 from a threshold model. Hinger et al. (2008) reported a heritability of 0.10 based on 4,524 serum ELISA tests of German Holsteins. Mortensen et al. (2004) used a sire model to analyze milk ELISA test data from 11,535 Danish Holstein cows, estimating a heritability of 0.10 , and reporting no correlation between ELISA scores and milk yields in a bivariate analysis. These heritability estimates are lower than those reported for milk production but are on a similar level to heritabilities reported for other disease traits. Zwald et al. (2004) reported heritability estimates for the pooled incidence rate of all diseases between calving and $50 \mathrm{~d}$ postpartum of 0.12 and 0.10 for first and all lactation analyses, respectively. These heritabilities are also similar to heritabilities used for productive life 
(PL), 0.08; SCS, 0.12; and daughter pregnancy rate (DPR), 0.04 (VanRaden, 2006) for US genetic evaluations.

Additional evidence of genetic variation for MAP infection resistance was reported by Settles et al. (2009). Two regions on chromosome 3 and a region on chromosome 9 were identified as associated with the presence of MAP in tissue and feces from analysis of 218 US Holsteins and 45,683 SNP.

The first objective of this study was to estimate genetic parameters of milk ELISA MAP test results from US Holstein cows using routinely collected DHIA field data. If there is significant additive genetic variation it may be possible to compute genetic evaluations for resistance to Johne's disease on a national level. The second objective was to calculate the correlations between the sire solutions for Johne's resistance and sire PTA for milk, fat, protein, SCS, DPR, PL, and Net Merit (NM). These correlations would show if there is an antagonism between traits currently selected for and Johne's resistance and may help adjust weights for these traits in NM taking into account the cost of Johne's disease.

\section{MATERIALS AND METHODS}

\section{Data}

A total of 50,493 milk ELISA tests from 654 herds were completed by Minnesota DHIA from November 2006 to February 2009. These ELISA tests (ParaCheck, Prionics AG, Zurich, Switzerland) measured the amount of antibodies against MAP as optical density (OD). Two negative controls were run with each batch of ELISA tests at the Minnesota DHIA laboratory. The function of the negative control is to adjust for variation in laboratory environmental effects on the ELISA tests. If the sample OD minus the average of the OD of negative controls was $\geq 0.1$, it was considered a positive test. Using the 0.1 threshold level gives a specificity of $99 \%$ and an overall sensitivity to MAP infection of $50 \%$. The sensitivity increases as the disease progresses from subclinical to clinical (ParaCheck, Prionics AG).

\section{Data Editing}

Test data from negative herds and from herds with fewer than 5 cows tested were excluded, and 43,841 ELISA tests representing 36,209 cows were sent to the Animal Improvement Programs Laboratory of USDA (Beltsville, MD) to be matched with pedigree information. Cow birth date, calving dates, and breed were also provided by the Animal Improvement Programs
Laboratory. After non-Holsteins and cows lacking sire ID were eliminated, the data set included 26,164 ELISA test records. Edits removed cows younger than 20 mo or older than 144 mo of age at time of ELISA testing. Finally, ELISA tests conducted at $<5$ DIM or $>1,100$ DIM were also eliminated, leaving 25,809 test records from 21,514 cows from 282 herds for analysis. The percentage of positive tests for MAP was $5.2 \%$. A total of 17,634 cows had 1 test; 3,504 had 2 tests; 344 had 3 tests; 28 had 4 tests; 2 cows had 5 tests; 1 cow had 6 tests; and only 1 animal was tested 7 times. For cows with multiple tests, the average interval between tests was $312 \mathrm{~d}$. Days in milk $>365 \mathrm{~d}$ was set to $365 \mathrm{~d}$. There were 65,852 animals in the pedigree file.

Daughter-dam pairs $(\mathrm{n}=2,040)$ and maternal halfsibs $(\mathrm{n}=4,082)$ in which both animals were tested for MAP were used to examine maternal effects. Summary statistics of the data are presented in Table 1. The MAP ELISA test results were analyzed both as a binary (positive for MAP $=1$ and negative $=0$ ) trait and as a linear (the natural log of the OD) trait. A logtransformation was applied to OD $[\ln (\mathbf{O D})]$ to correct for the non-normal distribution of scores. The $\ln (\mathrm{OD})$ statistics were similar to those reported by Mortensen et al. (2004) (Table 1). Younger cows had lower $\ln (\mathrm{OD})$, but there was considerable overlap in $\ln (\mathrm{OD})$ between the 3 age groups. The percentage of cows that tested positive for MAP by age category were: $2.7 \%$ (20 to $35.9 \mathrm{mo}$ of age at time of test); $5.4 \%$ (36 to $47.9 \mathrm{mo}$ ); and $6.8 \%$ ( $\geq 48 \mathrm{mo}$ ). Hinger et al. (2008) have reported a linear increase in MAP-positive cows from 2 to $3 \mathrm{yr}$ of age with prevalence declining in cows older than 5 yr. Lactations averaged 257 DIM at the time of testing, indicating that many cows were tested toward the end of lactation. A common practice in many herds was to test cows near dry off and then separate positive from negative cows during parturition.

\section{Statistical Analyses}

Preliminary analysis of fixed effects was done using PROC MIXED of SAS (SAS Institute, 2001). Genetic parameters and sire breeding values were estimated for $\ln (\mathrm{OD})$ using the REMLF90 computer program (Misztal et al., 2002). The binary analysis used Bayesian procedures implemented in the THRGIBBS1F90 package (Tsuruta and Misztal, 2006) assuming flat prior variances. A Gibbs chain of 30,000 samples was drawn and the first 5,000 rounds were discarded as burn-in. The following repeatability model was used with and without the maternal effects:

$$
\mathrm{y}=\mathbf{X} \boldsymbol{\beta}+\mathbf{S n}+\mathbf{Z a}+\mathbf{H p}+\mathbf{W m}+\mathrm{e},
$$


Table 1. Mean and distribution of the optical density (OD), logarithmic transformation of the OD [ln (OD)], negative control OD, age of cow at time of test, and DIM at time of test

\begin{tabular}{lcccc}
\hline Item & Mean & SD & Minimum & Maximum \\
\hline OD & 0.074 & 0.236 & 0.001 & 3.959 \\
Ln(OD) & & & & \\
All records & -3.511 & 1.028 & -6.908 & 1.376 \\
$20-35.9$ mo & -3.646 & 0.908 & -6.908 & 0.931 \\
$36-47.9$ mo & -3.511 & 1.039 & -6.908 & 1.376 \\
$\geq 48.0$ mo & -3.424 & 1.083 & -6.908 & 1.357 \\
Negative control OD & 0.063 & 0.036 & 0.003 & 0.216 \\
Age (mo) & 49.65 & 18.46 & 20 & 144 \\
DIM & 257.62 & 92.58 & 5 & 365 \\
\hline
\end{tabular}

${ }^{1}$ Age at time of ELISA test.

where $\mathrm{y}=$ ELISA test score $[\ln (\mathrm{OD})$ for the linear model and 0 or 1 for the threshold model]; $\boldsymbol{\beta}=$ a vector of covariates: DIM, age at test date, OD of average of negative controls, and age of dam at the time of cow birth (set to a maximum of 60 mo and only used in models with maternal effects); $\mathrm{n}=$ random effect of herd-year-season [seasons were defined as winter (December to February), spring (March to May), summer (June to August), and fall (September to November)]; $\mathrm{a}=$ animal effect; $\mathrm{p}=$ permanent environmental effect; $\mathrm{m}=$ maternal effect; $\mathrm{e}=$ random residual effect; and $\mathbf{X}$, $\mathbf{S}, \mathbf{Z}, \mathbf{H}$, and $\mathbf{W}$ are corresponding incidence matrices. Herd-year-season was included as a random variable rather than a fixed effect to facilitate convergence in the threshold model in which some herd-year-season groups contained only positive or negative tests.

Correlations between the EBV of $\ln (\mathrm{OD})$ for $154 \mathrm{Hol}-$ stein AI sires with at least 30 daughters in this study and their corresponding May 2009 USDA PTA for milk, fat, and protein yield, fat and protein percentages, PL, SCS, DPR, and NM were calculated with PROC CORR of SAS (SAS Institute, 2001). The distribution of sires by number of daughters is shown in Figure 1. The sires for this part of the study averaged 81 daughters (median $=60$ ) for the MAP genetic evaluations, compared with an average of 21,129 daughters for their USDA genetic evaluations.

To estimate approximate genetic correlations between $\ln (\mathrm{OD})$ and USDA traits, the procedure referenced by Onyiro et al. (2008) was used:

$$
\hat{\mathrm{r}}_{\mathrm{g} 1,2}=\frac{\sqrt{\left\{\sum \mathrm{RL}_{1}\right\} \times\left\{\sum \mathrm{RL}_{2}\right\}}}{\sum\left\{\mathrm{RL}_{1} \times \mathrm{RL}_{2}\right\}} \times \mathrm{r}_{1,2},
$$

where $\mathrm{RL}_{1}$ and $\mathrm{RL}_{2}=$ reliabilities of traits 1 and $2 ; \hat{\mathrm{r}}_{\mathrm{g} 1,2}$ $=$ approximate genetic correlation between traits 1 and 2 ; and $\mathrm{r}_{1,2}=$ correlation between EBV or PTA for traits 1 and 2 .

The standard errors of correlations were estimated using the formula below:

$$
S E=\sqrt{\frac{1-\hat{\mathrm{r}}_{\mathrm{g} 1,2}^{2}}{n-2}},
$$

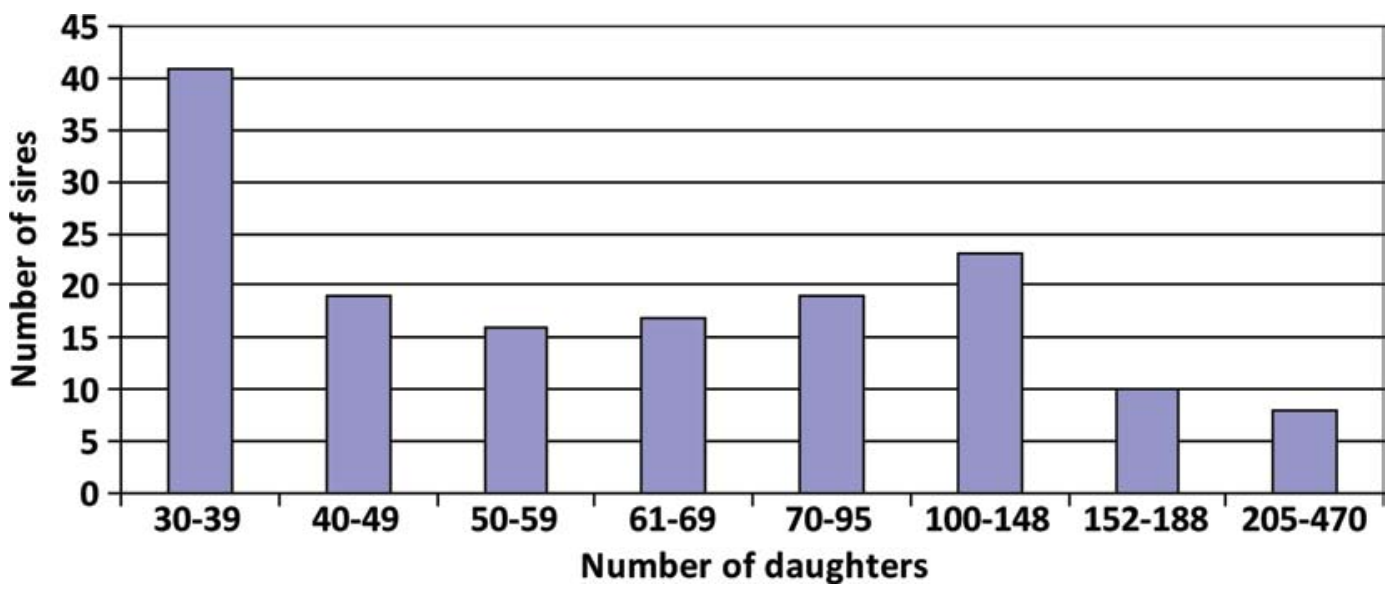

Figure 1. Distribution of the 154 sires that had at least 30 daughters in the data set by number of daughters. Color version available in the online PDF. 
Table 2. Variance components for repeatability model fitting linear and threshold models

\begin{tabular}{lcc}
\hline Variance component & Linear model & Threshold model $( \pm$ SE) \\
\hline Herd-year-season variance & 16.530 & $0.9848 \pm 0.04869$ \\
Additive genetic variance & 0.057 & $0.0030 \pm 0.00054$ \\
Permanent environment variance & 0.217 & $0.0163 \pm 0.00081$ \\
Residual error variance & 0.442 & $0.0272 \pm 0.00058$ \\
Heritability & 0.080 & 0.0645 \\
Repeatability & 0.383 & 0.4151 \\
\hline
\end{tabular}

where $n=$ number of sires with records. All of the reliabilities of the USDA PTA for the 154 Holstein AI sires were approaching 99\% or higher. Approximate reliabilities of EBV of $\ln (\mathrm{OD})$ for the 154 Holstein sires were estimated by $\mathrm{P} \times \mathrm{h}^{2} /\left(4+\mathrm{P} \times \mathrm{h}^{2}\right)$, where $\mathrm{P}=$ number of daughters with $\ln (\mathrm{OD})$ records (Calo et al., 1973).

\section{RESULTS AND DISCUSSION}

As DIM increased, $\ln (\mathrm{OD})$ increased $(P<0.001)$, in agreement with Nielsen et al. (2006) who reported that the likelihood of testing positive for Johne's increases with increasing DIM in affected animals. Age at test date was also positively associated with an increasing $\ln (\mathrm{OD})(P<0.001)$. Because paratuberculosis has a very long incubation period, older cows are more likely than younger cows to test positive (Nielsen et al., 2006). Age of dam at the time of cow birth was not significant $(P=0.66)$ in the preliminary analysis but was left in the model because of its potential influence on the estimation of maternal effects. The quadratic effects of DIM and age at test date were not significant in the preliminary analysis and were not used in the models for estimation of variance components.

Variance components, heritabilities, and repeatabilities from the linear and threshold models without maternal effects in the model are presented in Table 2. The phenotypic variance used to calculate heritability was the sum of the genetic, permanent environment, and residual variances. The heritabilities of 0.080 for the linear model and 0.0645 for the threshold model are on the lower end of the range reported in previous stud- ies for which heritability estimates ranged from 0.06 to 0.16. for milk and serum ELISA for MAP (Koets et al., 2000; Nielsen et al., 2002; Mortensen et al., 2004; Gonda et al., 2006; Hinger et al., 2008). The additive genetic variance estimated in the threshold model of 0.0030 was 5 times the standard error, indicating that there may be significant additive genetic variation for this trait. The linear model was run with and without the genetic effect to test the statistical significance of the genetic variance. The likelihood ratio test (Casella and Berger, 1990) indicated that the genetic variance was significantly greater than zero $(P<0.001)$.

The heritability from the linear model including maternal effects was similar at 0.075 , but the heritability estimate for the threshold model was higher at 0.0946 (Table 3). This was caused by an increase in additive genetic variance from $0.0030 \pm 0.00054$ to $0.0045 \pm$ 0.00073. Herd-year-season and permanent environmental variance estimates did not significantly change by including maternal effects in the model.

Common maternal sources of variation explained $1.3 \%$ of the variation for the linear model and $2.29 \%$ of total variation for the threshold model (Table 3). The maternal effects variance from the threshold model was $0.0011 \pm 0.00035$. Possible causes of a maternal effect include intrauterine infection of the fetus (Sweeney et al., 1992), and the calf can orally ingest MAP from the dam through colostrum, milk, or feces at parturition. Additive genetic variances increased when maternal effects were included in the threshold model but did not change for the linear model. However, for the linear model, inclusion of maternal effects resulted in lower estimates of Akaike's information criterion, indicating

Table 3. Variance components for maternal repeatability model fitting linear and threshold models

\begin{tabular}{lcc}
\hline Variance component & Linear model & Threshold model ( \pm SE) \\
\hline Herd-year-season variance & 16.610 & $0.9465 \pm 0.0457$ \\
Additive genetic variance & 0.054 & $0.0045 \pm 0.00073$ \\
Permanent environment variance & 0.210 & $0.0152 \pm 0.00085$ \\
Maternal effects variance & 0.009 & $0.0011 \pm 0.00035$ \\
Residual error variance & 0.446 & $0.0273 \pm 0.00065$ \\
Heritability & 0.075 & 0.0946 \\
Variation explained by maternal effects (\%) & 0.013 & 0.0229 \\
Repeatability & 0.380 & 0.4329 \\
\hline
\end{tabular}


an improved fit of the model to the data. Further research, which may include data collected over a longer time period so that more maternal relatives have tests over their complete lifetimes, is needed to decide how best to account for maternal effects when computing MAP ELISA evaluations. In this study, data were collected only over a 27-mo period, which would affect the age structure of the daughter-dam pairs and maternal half-sibs. Many of the animals in these pairings were tested at young ages, possibly before the disease had a chance to fully manifest itself. Results from this study would imply that including maternal effects in the models for genetic evaluations is appropriate. The cost of including maternal effects in the model is minimal. On the other hand, Mortensen et al. (2004) found that maternal effects accounted for less than $1 \%$ of the variation in a study in which the majority of cows were tested in second and later parities. They concluded that maternal effects were not a significant source of variation.

Repeatabilities were similar for the various models and ranged from 0.380 to 0.433 , which is slightly lower than the repeatability for lactational milk production but higher than the repeatabilities for DPR or SCS. Nielsen and Ersbøll (2006) indicated that repeated milk ELISA testing for Johne's has more value for younger cows than for older cows and suggested monthly tests for cows younger than 4 yr of age.

Results from this study do not provide evidence to recommend a linear model over a threshold model for genetic evaluation. However, Hinger et al. (2008) concluded that $\ln (\mathrm{OD})$ should be used rather than MAP status as a binary trait because of the greater heritability and more robust parameter estimates for the estimation of breeding values. Another consideration when using national or international data is that different commercial companies that provide the ELISA test kits may set the threshold value at which a cow is declared positive at different levels.

Correlations between the EBV for $\ln (\mathrm{OD})$ from the model without maternal effects for the 154 sires with at least 30 daughters with $\ln (\mathrm{OD})$ records in our data, and sire USDA PTA are presented in Table 4, along with approximate genetic correlations. The approximate genetic correlations between $\ln (\mathrm{OD})$ and USDA PTA traits were approximately $35 \%$ greater in magnitude than the raw correlations between $\ln (\mathrm{OD}) \mathrm{EBV}$ and USDA sire PTA. The correlations between USDA traits for our 154 sires were similar to the correlations from national data reported by VanRaden (2006). All correlation estimates indicate no antagonism between selection for these USDA traits and Johne's resistance as measured by $\ln (\mathrm{OD})$ for MAP infection. There were desirable correlations of fat and protein yields, with

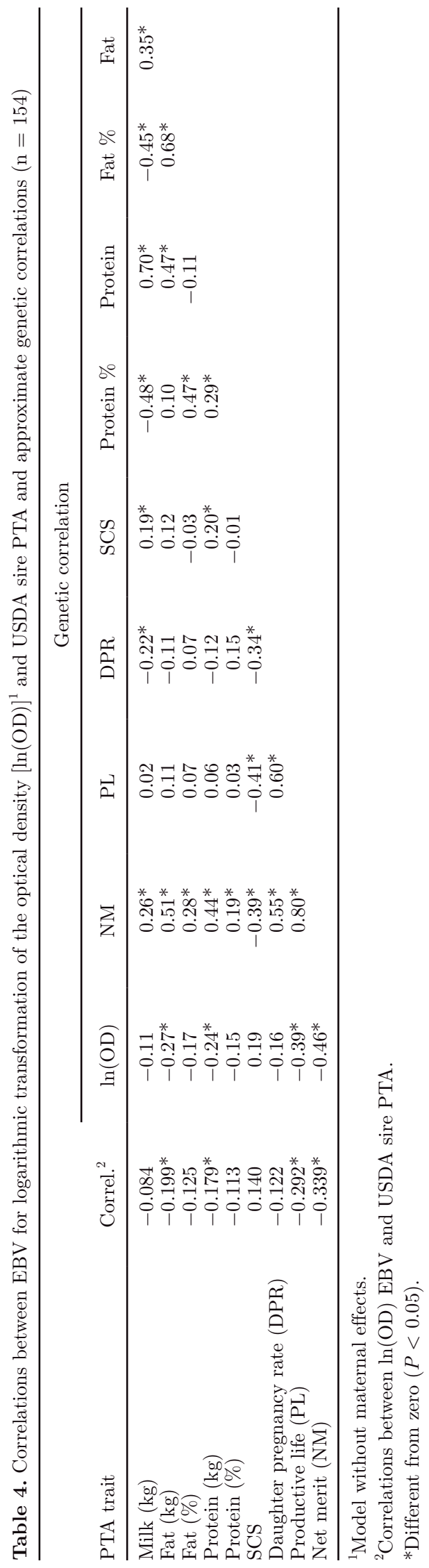

Journal of Dairy Science Vol. 93 No. 4, 2010 
$\ln (\mathrm{OD})$ of -0.27 and -0.24 , respectively. However, the correlation between milk yield and $\ln (\mathrm{OD})$ was lower and not statistically significant at -0.11 . This was somewhat unexpected given the high genetic correlations of milk with fat and protein of 0.45 and 0.81 , respectively. However, Mortensen et al., (2004) also reported a nonsignificant genetic correlation of -0.037 between $\ln (\mathrm{OD})$ and daily milk yield.

Productive life and NM were most strongly correlated with the sire solutions for $\ln (\mathrm{OD})$ at -0.39 and -0.46 , respectively. Even though correlations do not imply cause and effect, these correlations suggest that selection for PL and NM may increase genetic resistance to Johne's disease. Net Merit is a composite of the other USDA traits and is desirably correlated with these traits (Table 4). It seems logical that NM would be at least moderately correlated with $\ln (\mathrm{OD})$ given that these other traits were all correlated in the desirable direction with $\ln (\mathrm{OD})$.

The desirable correlations reported here may have a common underlying cause. Cows that have genetically superior immune systems may be more resistant to MAP infection. These cows with superior immune systems would also be expected to remain healthier to produce more fat and protein, have lower SCS, higher pregnancy rates, longer productive lives, and more total economic merit.

A study by NAHMS (1997) calculated economic losses associated with Johne's disease, including reduced milk production, decreased salvage value for affected cattle, increased culling, and greater mortality. Losses were $\$ 40$ per cow in Johne's-positive herds with less than $10 \%$ of culls showing clinical signs of the disease, and $\$ 227$ per cow in herds with $10 \%$ or more symptomatic culls. These costs should be considered when updating the economic values used in the calculation of the lifetime net merit, fluid merit, and cheese merit indices. The results of this study suggest that the weight placed on longevity in the indices might increase because Johne's status and PL are negatively genetically correlated.

\section{CONCLUSIONS}

This study found heritabilities ranging from 0.0645 to 0.0946 for antibody production to MAP using routinely collected DHI field data. These heritability estimates and significant estimates of additive genetic variances indicate that it is possible to compute genetic evaluations for resistance to Johne's disease. In the absence of genetic evaluations for resistance to Johne's disease, selection for PL and NM will result in cows genetically more resistant to the disease.

\section{ACKNOWLEDGMENTS}

The authors thank Minnesota DHIA for providing milk ELISA test data. We also gratefully acknowledge Ignacy Misztal and Shogo Tsuruta at the University of Georgia (Athens) for use of the REMLF90 and THRGIBBS1F90 computer programs. Two anonymous reviewers provided very useful suggestions for this manuscript.

\section{REFERENCES}

Calo, L. L., R. E. McDowell, L. D. VanVleck, and P. D. Miller. 1973. Genetic aspects of beef production among Holstein-Friesians pedigree selected for milk production. J. Anim. Sci. 37:676-682.

Casella, G., and R. L. Berger. 1990. Statistical Inference. Duxbury Press, Belmont, CA.

Gonda, M. G., Y. M. Chang, G. E. Shook, M. T. Collins, and B. W Kirkpatrick. 2006. Genetic variation of Mycobacterium avium ssp. paratuberculosis infection in US Holstein. J. Dairy Sci. 89:18041812

Hinger, M., H. Brandt, and G. Erhardt. 2008. Heritability estimates for antibody response to Mycobacterium avium subspecies paratuberculosis in German Holstein cattle. J. Dairy Sci. 91:32373244

Koets, A. P., G. Adugna, L. L. G. Janss, H. J. Van Weering, C. H. Kalis, G. H. Wentink, V. P. M. G. Rutten, and Y. H. Shukken. 2000. Genetic variation of susceptibility to Mycobacterium avium ssp. paratuberculosis infection in dairy cattle. J. Dairy Sci. $83: 2702-2708$

Kovich, D. A., S. J. Wells, and K. Friendshuh. 2006. Evaluation of the voluntary Johne's disease herd status program as a source of replacement cattle. J. Dairy Sci. 89:3466-3470.

Misztal, I., S. Tsuruta, T. Strabel, B. Auvray, T. Druet, and D. H. Lee. 2002. BLUPF90 and related programs. Pages 33:743-744 in Proc. 7th World Congr. Genet. Appl. Livest. Prod., Montpelier, France. CD-ROM Commun. 28-07.

Mortensen, H., S. S. Nielsen, and P. Berg. 2004. Genetic variation and heritability of the antibody response to Mycobacterium avium subspecies paratuberculosis in Danish Holstein cows. J. Dairy Sci. $87: 2108-2113$

NAHMS. 1997. Johne's Disease on U.S. Dairy Operations. USDAAPHIS-VS, CEAH, National Animal Health Monitoring System. Fort Collins, CO. http://www.aphis.usda.gov/vs/ceah/ncahs/ nahms/dairy/dairy96/DR96john.pdf. Accessed August 2009.

NAHMS. 2007. Johne's Disease on U.S. Dairy Operations, 1991-2007. USDA-APHIS-VS, CEAH, National Animal Health Monitoring System. Fort Collins, CO. http://www.aphis.usda.gov/vs/ceah/ ncahs/nahms/dairy/dairy07/Dairy2007_Johnes.pdf. Accessed Sept. 2009.

Nielsen, H. M., L. G. Christensen, and J. Ødegård. 2006. A method to define breeding goals for sustainable dairy cattle production. J. Dairy Sci. 89:3615-3625.

Nielsen, S. S., and A. K. Ersbøll. 2006. Age at occurrence of Mycobacterium avium subspecies paratuberculosis in naturally infected dairy cows. J. Dairy Sci. 89:4557-4566.

Nielsen, S. S., Y. T. Gröhn, and C. Enevoldsen. 2002. Variation of the milk antibodies response to paratuberculosis in naturally infected dairy cows. J. Dairy Sci. 85:2795-2802.

Onyiro, O. M., L. J. Andrews, and S. Brotherstone. 2008. Genetic parameters for digital dermatitis and correlations with locomotion, production, fertility traits, and longevity in Holstein-Friesian dairy cows. J. Dairy Sci. 91:4037-4046.

SAS Institute. 2001. SAS/STAT User's Guide. Release 8.02. SAS Institute Inc., Cary, NC. 
Settles, M., R. Zanella, S. D. McKay, R. D. Schnabel, J. F. Taylor, R. Whitlock, Y. Schukken, J. S. Van Kessel, J. M. Smith, and H. Neibergs. 2009. A whole genome association analysis identifies loci associated with Mycobacterium avium ssp. paratuberculosis infection status in US Holstein cattle. Anim. Genet. 40:655-662.

Sweeney, R. W., R. H. Whitlock, and A. E. Rosenberger. 1992 Mycobacterium paratuberculosis isolated from fetuses of infected cows not manifesting signs of the disease. Am. J. Vet. Res. $53: 477-480$.

Tsuruta, S., and I. Misztal. 2006. THRGIBBS1F90 for estimation of variance components with threshold-linear models. Comm. 2731 in Proc. 8th World Congr. Genet. Appl. Livest. Prod., Belo Horizonte, Brazil. CD-ROM Commun. 27-31.
VanRaden, P. M. 2006. Net merit as a measure of lifetime profit: 2006 revision. Animal Improvement Programs Laboratory, ARSUSDA, Beltsville, MD. http://aipl.arsusda.gov/reference/nmcalc. htm Accessed September 2009.

Wells, S. J., S. L. Ott, and A. Hillberg Seitzinger. 1998. Key health issues for dairy cattle-New and old. J. Dairy Sci. 81:30293035 .

Zwald, N. R., K. A. Weigel, Y. M. Chang, R. D. Welper, and J. S. Clay. 2004. Genetic selection for health traits using producerrecorded data. I. Incidence rates, heritability estimates, and sire breeding values. J. Dairy Sci. 87:4287-4294. 